\title{
LATAR BELAKANG PENDIDIKAN ORANG TUA DAN HELICOPTER PARENTING DI JAKARTA
}

\author{
Maria Josephine $^{1}$, Shinta Doriza ${ }^{2}$, Nurlaila Abdullah Mashabi ${ }^{3}$ \\ Universitas Negeri Jakarta \\ Email :mjosephineaprilia@gmail.com
}

\begin{abstract}
The research objective was to obtain an overview of the relationship between the socio-economic conditions of the family with helicopter parenting. The socio-economic conditions in this article include: education, work, and income. The research method used the survey method. The study population was 4872 students using simple random sampling, so the number of research samples was 356 respondents. The results of data hypothesis testing using the correlation coefficient eta (I) indicate that overall it is significantly positive. This research has implications so that parents are not too involved in children's lives. Children with such parenting can cause them to become independent, unable to socialize well, and even fall into illegal drugs.
\end{abstract}

Keywords: Family Socio-Economic Conditions, Helicopter Parenting, Education Parents Backgroud

\section{Abstrak}

Tujuan penelitian untuk memperoleh gambaran tentang hubungan antara kondisi sosial ekonomi keluarga dengan helicopter parenting. Kondisi sosial ekonomi pada artikel ini antara lain: pendidikan, pekerjaan, dan pendapatan. Metode penelitian menggunakan metode survei. Populasi penelitian sebesar 4872 mahasiswa dengan menggunakan simple random sampling maka jumlah sampel penelitian sebanyak 356 responden. Hasil uji hipotesis data dengan menggunakan koefisien korelasi eta (П) menunjukkan bahwa secara keseluruhan signifikan positif. Penelitian ini berimplikasi agar para orang tidak terlalu terlibat pada kehidupan anak. Anak dengan pola asuh tua seperti itu dapat menyebabkan anak menjadi tidak mandiri, tidak dapat bersosialisasi dengan baik, bahkan dapat terjerumus dalam obat-obatan terlarang.

Kata Kunci: Kondisi Sosial Ekonomi Keluarga, Helicopter Parenting, Pendidikan Orang Tua

\section{PENDAHULUAN}

Keluarga merupakan unit terkecil dalam masyarakat. Keluarga yang lengkap terdiri dari ayah, ibu dan anak yang tinggal di dalam satu rumah tersebut mereka akan berbagi kasih sayang, perhatian, dan pendidikan agama maupun sosial. Makna keluarga adalah tafsir, gambaran, dan pandangan yang dikonstruksi secara kolektif oleh anggota keluarga saat mereka berinteraksi satu sama lain; saat mereka berbagi waktu, ruang, dan pengalaman hidup; dan saat mereka berbicara satu sama lain dan berdialog tentang pengalaman (Patterson \& Garwick, 1994). Keluarga merupakan faktor utama dalam prestasi belajar anak baik dalam akademik maupun nonakademik. Keluarga memiliki kewajiban utama dalam pendidikan anak. Sebelum anak mendapatkan pendidikan dari sekolah, pendidikan dari keluarga ialah hal yang utama dan pertama yang didapatkan anak. Pendidikan di sekolah hanya sebagai tempat anak berproses sementara waktu. 
Keluarga mempunyai latar belakang yang berbeda. Faktor latar belakang keluarga secara umum dilihat berdasarkan pencapaian Pendidikan orang tua (Björklund \& Salvanes, 2011; Grätz, et.al., 2019; Impicciatore \& Tosi, 2019; Jeong \& Eamon, 2009; Wang, 2004), memegang peranan penting dalam pembentukan sikap dan tingkah laku anak (Doriza, Jannah, Yulastri, Maulida, \& Patrisia, 2018). Keluarga yang mempunyai Pendidikan yang tinggi akan menjadikan latar belakang tersebut menjadi keluarga yang terpandang. Pendidikan juga termasuk salah satu dari indikator sosial ekonomi keluarga (Camelia, Devi, \& Doriza, 2016), dimana keluarga yang mempunyai sosial ekonomi yang tinggi juga akan berpengaruh ke latar belakang keluarga tersebut terpandang atau tidak.

Kondisi sosial ekonomi keluarga berhubungan erat dengan pemasukan dari keluarga itu sendiri. Kondisi sosial ekonomi tidak terlepas dari ekonomi berarti kedudukan suatu individu dan keluarga berdasarkan unsur-unsur ekonomi. Selain itu, faktor utama dalam penentuan kelas sosial adalah Pendidikan orang tua, pekerjaan orang tua, pendapatan rumah tangga dan kondisi rumah tangga (Galobardes, Shaw, Lawlor, Lynch, \& Smith, 2006).

Orang tua menginginkan kesuksesan pada anak, mereka berusaha menyediakan layanan keluarga guna memenuhi kebutuhan semua anggota keluarga (Doriza, 2015) khususnya anak mereka. Segala sesuatu dilakukan agar anak mendapatkan masa depan yang cerah. Untuk menunjang kebutuhan pada anak memerlukan biaya yang tidak sedikit. Banyak orang tua dengan kondisi sosial ekonomi keluarga tinggi yang menyekolahkan anak mereka ke tempat yang bagus dan terpandang. Namun tidak sedikit pula keluarga dengan kondisi sosial ekonomi keluarga menengah juga berjerih payah mencari pendapatan lebih demi menyekolahkan anak mereka ke sekolah yang bagus dan terpandang.

Meskipun keterlibatan orangtua dalam kehidupan anak selama ini dilihat sebagai hal yang baik bagi perkembangan anak, nampaknya keterlibatan orang tua yang tinggi serta intens dan seringkali ditemukan pada orangtua dari generasi milenial saat ini justru dilihat sebagai hal yang negatif. Membentuk kepribadian anak menjadi baik harus di ikuti dengan parenting yang baik pula. Seiring dengan 
berkembangnya zaman, parenting yang diterapkan juga harus disesuaikan. Zaman ini sudah memasuki periode generasi milenial, yaitu generasi yang lahir pada kisaran tahun 1981-2000. deBard et al. (Odenweller, BoothButterfield, \& Weber, 2014) menyatakan generasi ini seringkali dihubungkan dengan berbagai karakteristik, seperti generasi yang spesial dan terlindungi serta memiliki orangtua yang berusaha melindungi mereka serta lebih terlibat dalam mengatur berbagai aspek kehidupan anak.

Parenting dengan orang tua yang terlalu terlibat dalam kehidupan anak merupakan jenis parenting yang sudah banyak diterapkan pada zaman milenial, parenting ini disebut dengan sebutan helicopter parenting. Helicopter parenting pada dasarnya merupakan sebuah kecenderungan karakteristik pola asuh yang sebenarnya dilakukan dengan niat yang baik (seperti untuk memberi dukungan dan kasih sayang), namun orangtua biasanya melakukan hal tersebut melebihi batas kewajaran (Lemoyne \& Buchanan, 2011). Helicopter parenting mengacu pada keterlibatan yang berlebihan dari orang tua di sekitar anak-anak, menyelamatkan anak dari bahaya dan mencegah anak mengalami kegagalan.

Berdasarkan data dan fakta di atas dapat dilihat bahwa latar belakang keluarga yang berfokus pada pencapaian pendidikan orang tua juga memiliki peran pada parenting yang diberikan pada anak, maka penulis ingin melihat adakah hubungan latar belakang keluarga khususnya pada pencapaian pendidikan dengan helicopter parenting.

\section{Helicopter Parenting}

Helicopter Parenting mengacu pada keterlibatan orang tua yang berlebihan dalam kehidupan anak (Khairunnisa \& Trihandayani, 2018; Lemoyne \& Buchanan, 2011). Perilaku tidak terkontrol tanpa memberikan otonomi yang memadai dalam kehidupan dan keputusan anak sampai mencapai kedewasaan (Jang, J., Lee, S., Sung, M., \& Lee, 2016; Kwon, K.-A., Yoo, G., \& Bingham, 2016; Lee \& Kang, 2018; Okray, 2016; Segrin, Woszidlo, Givertz, Bauer, \& Murphy, 2012). Pengasuhan helicopter secara positif terkait dengan keterlibatan orang tua dan anak namun berhubungan negatif dengan pemberian otonomi dari orang tua (Padilla-Walker \& Nelson, 2012), keterlibatan yang berlebihan akan merusak perkembangan 
anak dan kemungkinan besar mempengaruhi kemandirian dan kemajan diri anak-anak (Kantrowitz \& Peg, 2006; Lemoyne \& Buchanan, 2011; E. E. Maccoby, 2007; Eleanor E. Maccoby, 1992; Marano, 2004), efikasi diri yang rendah, keterasingan dari teman sebaya, dan kurangnya kepercayaan di antara teman sebaya (Ingen, et.al., 2015).

Orang tua helicopter atau orang tua seperti helicopter yang berperilaku melayang tepat di atas anak, dalam artian orang tua yang di luar jangkauan, memberi perhatian, sangat dekat dengan anak, berusaha menjauhkan anak (Ingen, et.al., 2015), juga melayang di atas institusi Pendidikan tinggi dan kemungkinan implikasi yang dapat mempengaruhi pembelajaran sampai pemberi kerja di masa depan anak (Vinson, 2012)

\section{Latar Belakang Pendidikan Orang} Tua

Faktor latar belakang keluarga secara umum dilihat berdasarkan pencapaian Pendidikan orang tua (Björklund \& Salvanes, 2011; Grätz, et.al., 2019; Impicciatore \& Tosi, 2019; Jeong \& Eamon, 2009; Wang, 2004). Pendidikan menjadi salah satu dari indikator sosial ekonomi. Salah satu efek status sosial ekonomi pada prestasi akademik terutama diucapkan dalam sistem sekolah terlacak Jerman, di mana pendidikan sangat terkait dengan sumber daya sosial-ekonomi keluarga, dan rekomendasi sekolah dipengaruhi oleh status sosial orang tua (Klieme, E., Artelt, C., Hartig, J., Jude, N., Köller, O., Prenzel, M., Schneider, W., \& Stanat, 2010). Literatur menunjukkan bahwa dukungan orang tua berdasarkan pendidikan yang tinggi sehingga otomatis memiliki penghasilan yang tinggi akan cenderung menginvestasikan lebih banyak modal sosial dalam mendukung anak-anak secara intensif dan lebih berkualitas secara akademis daripada orang tua dengan sosial ekonomi rendah (Hill, N. E., \& Taylor, 2004; Hyde, J. S., Else-Quest, N. M., Alibali, M. W., Knuth, E., \& Romberg, 2006; Ream, R. K., \& Palardy, 2008)

\section{METODOLOGI PENELITIAN}

Responden dalam penelitian ini adalah 356 mahasiswa Universitas Negeri Jakarta angkatan 2018 berusia 19-21 tahun. Rentang usia responden penelitian mahasiswa Universitas Negeri Jakarta angkatan 2018, diketahui bahwa usia mahasiswa yang menjadi responden 
didominasi oleh mahasiswa yang berusia 19 tahun sebanyak 284 orang sedangkan terendah berada pada usia 21 tahun sebanyak 11 orang. Jumlah anak dari orang tua responden dengan persentase tertinggi sebesar 32\% (114 orang), dan persentase terendah memiliki jumlah anak 6 sebesar $3 \% \quad(11$ orang). Responden dipilih secara acak dan para responden menyelesaikan kuesioner dengan melakukan pengisian melalui Google Form.

Jenis penelitian menggunakan penelitian kuantitatif assosiatif. Metode dalam penelitian ini adalah survei korelasional. Metode survei dengan pendekatan korelasional dilakukan agar dapat mengetahui dan ditentukan variabel mana yang berkorelasi, untuk mencari ada tidaknya kaitan antara latar belakang Pendidikan orang tua dengan helicopter parenting serta untuk mengetahui seberapa erat kaitan antar variabel satu dengan variabel lainnya, penelitian ini menggunakan penelitian survei dengan pendekatan korelasional. Penelitian dilaksanakan di Universitas Negeri Jakarta, penelitian dilaksanakan pada bulan Desember 2019 sampai dengan Januari 2020.

Populasi sasaran dalam penelitian ini adalah mahasiswa Universitas Negeri
Jakarta angkatan 2018. Adapun jumlah dari populasi mahasiwa ialah 4.872 mahasiswa dengan alasan karena mahasiwa dari Universitas Negeri Jakarta angkatan 2018 berasal dari kondisi sosial ekonomi keluarga yang berbeda-beda, serta latar belakang dari keluarga yang berbeda. Penelitian ini menggunakan kuesioner yang dilaksanakan di Universitas Negeri Jakarta berada di Jalan Rawamangun, Jakarta Timur.

Penelitian menggunakan teknik pengambilan data metode probability sampling yaitu Propotionate Stratified Random Sampling. Teknik ini digunakan karena populasi mempunyai anggota/unsur yang tidak homogen dan berstrata secara proposional. Teknik daerah ini digunakan dalam dua tahap, yaitu pertama menentukan sampel daerah dan sampel berikutnya menentukan orang-orang yang ada pada daerah itu secara sampling juga. Adapun jumlah populasi yang berhasil ditemukan sebanyak 4872 responden sampel yang diambil dengan teknik Propotionate Stratified Random Sampling berjumlah 356 responden yang menggunakan rumus slovin. Dalam penelitian ini kesalahan yang digunakan peneliti adalah sebesar 5\% atau 0,05.Teknik 
pengolahan data dan analisis data yang dilakukan menggunakan SPSS dan Ms. Excel.

Pendidikan orang tua didefinisikan sebagai salah satu dari faktor penentu kelas sosial dengan indikator tingkat pendidikan akhir yang di tempuh ayah dan ibu, yaitu SD/ MI/ Sederajat; SMO/ sederajat; SMA/ SMK/ MA/ Sederajat; dan Universitas/ Sederajat.

\section{Tabel 1. Pendidikan Terakhir Ayah dan Ibu}

\begin{tabular}{|c|c|c|}
\hline $\begin{array}{l}\text { Pendidikan } \\
\text { Terakhir Ayah }\end{array}$ & Frekuensi & Persentase \\
\hline SD/MI/Sederajat & 19 & $5 \%$ \\
\hline SMP/ Sederajat & 16 & $5 \%$ \\
\hline $\begin{array}{l}\text { SMA/SMK/MA/ } \\
\text { Sederajat }\end{array}$ & 142 & $40 \%$ \\
\hline $\begin{array}{l}\text { Universitas/ } \\
\text { Sederajat }\end{array}$ & 179 & $50 \%$ \\
\hline Jumlah & 356 & $100 \%$ \\
\hline $\begin{array}{l}\text { Pendidikan } \\
\text { Terakhir Ibu }\end{array}$ & Frekuensi & Persentase \\
\hline SD/MI/Sederajat & & $9 \%$ \\
\hline SMP/ Sederajat & 5 & $1 \%$ \\
\hline $\begin{array}{l}\text { SMA/SMK/MA/ } \\
\text { Sederajat }\end{array}$ & 146 & $41 \%$ \\
\hline $\begin{array}{l}\text { Universitas/ } \\
\text { Sederajat }\end{array}$ & 175 & $49 \%$ \\
\hline Jumlah & 356 & $100 \%$ \\
\hline
\end{tabular}

Helicopter parenting di defeinisikan sebagai gaya pengasuhan oang tua dengan keterlibatan yang tinggi pada anak. Instrumen Helicopter Parenting Instrument (HPI) Uji oleh Odenweller, K. G., Booth-Butterfield, M., \& Weber,
K. (2014). Dengan jumlah 15 item dan hasil validitas ialah 14 item valid dan 1 item tidak valid. Begitupun dengan hasil normalitas data yang menghasilkan semua data terdistribusi dengan normal. 
Tabel 2. Statistik Deskriptif Helicopter Parenting Dan Latar Belakang Pendidikan

\begin{tabular}{lllll}
\hline Instrumen & $\boldsymbol{\alpha}$ & $\mathbf{M}$ & SD & $\mathbf{1}$ \\
\hline 1.Odenweller & 0.78 & 36.89 & 20.10 & \\
(2014 & & & & \\
Helicopter & & & & \\
Parenting & & & & \\
Instrument & & & & \\
\hline Latar & & & & \\
Belakang & & & & \\
Pendidikan & & & & \\
\hline 2.Pendidikan & 0.766 & 26.23 & 4.08 & 0.443 \\
\hline
\end{tabular}

Catatan: Instrumen menggunakan skala likert

Hasil pengujian penelitian ini helicopter parenting adalah berbanding menunjukan rata-rata skor besarnya nilai $\mathrm{R}$ kedua variable ialah $0.600-0.800$ yang termasuk dalam kategori tinggi.

Korelasi bertujuan untuk menentukan derajat atau kekuatan hubungan antar variabel. Dalam uji korelasi menggunakan eta (n) pada variabel kondisi sosial ekonomi dan helicopter parenting. Berdasarkan hasil perhitungan, dapat dilihat dibawah ini.

\section{HASIL DAN PEMBAHASAN}

Hasil pengujian korelasi dihitung dengan menggunakan rumus eta (n), diketahui bahwa korelasi eta antara tingkat pendidikan dengan helicopter parenting adalah sebesar 0,443. Tanda positif menunjukkan bahwa korelasi yang terjadi antara tingkat pendidikan dengan lurus, artinya semakin tinggi tingkat pendidikan maka akan semakin tinggi terjadinya helicopter parenting.

Tingkat pendidikan memiliki nilai $\mathrm{T}_{\text {hitung }}$ sebesar 9,30 dengan $T_{\text {tabel }}$ sebesar 1,64 karena nilai $\mathrm{T}_{\text {hitung }}$ lebih besar dari $\mathrm{T}_{\text {tabel }}$ maka Ho ditolak. Artinya, tingkat pendidikan berhubungan positif dan signifikan dengan helicopter parenting.

Hasil ini menujukkan bahwa semakin tinggi tingkat pendidikan orang tua maka mereka semakin kuat mereka terlibat bahkan berlebihan dalam kehidupan anak (Khairunnisa \& Trihandayani, 2018; Lemoyne \& Buchanan, 2011). Menurut Rainey (2016) orang tua helicopter jarang di luar jangkauan, memberi perhatian sangat dekat pada 
anak mereka, dan bergegas untuk mencegah bahaya, terutama di Lembaga Pendidikan anak dewasa (Van Ingen et al., 2015).

Secara empiris, hasil analisis crosstab diketahui bahwa orang tua responden didominasi pada tingkat pendidikan Diploma/Sarjana. Selain itu, dari hasil analisis crosstab juga diketahui dimensi tertinggi pada helicopter parenitng adalah kehangatan orang tua. Hasil penelitian ini sesuai dengan hasil penelitian Sewell dan rekan-rekannya yaitu harapan pendidikan telah lama diidentifikasi sebagai kendaraan penting di mana orang tua berharap pada masa depan anak (Sewell, William H., 1975)

\section{PENUTUP}

Hasil penelitian memberikan bukti yang empiris dalam pengasuhan helicopter parenting pada jaman milenial. Orang tua masih terlibat dalam perkembangan dan pendidikan anak mereka khususnya bagi orang tua yang memiliki pendidikan tinggi. Penelitian ini adalah untuk mengurangi motivasi pada orang tua dengan tingkat pendidikan yang tinggi untuk tidak selalu 'menyetir' anak-anak mereka dengan melakukan helicopter parenting. Sebaiknya para orang tua ditanamkan bagaimana cara mendekatkan diri dengan para anak dengan cara yang sewajarnya agar anak tidak merasa dirugikan dan percaya pada diri sendiri. Apabila para orang tua terus menerus menerapkan helicopter parenting pada penerapan pola asuh pada anak maka akan berdampak anak menjadi tidak mandiri dan tidak bisa mengenali dirinya sendiri. Penelitian yang dilakukan oleh peneliti tedapat korelasi antara latar belakang keluarga berdasarkan Pendidikan orang tua dengan helicopter parenting. Terdapat hubungan yang positif dan signifikan antara lain tingkat pendidikan memperoleh korelasi sebesar 0,443. Jika sesorang mempunyai latar belakang pendidikan maka kemungkinan untuk melakukan helicopter parenting juga tinggi.

Keterbasan penelitian ini berada pada latar belakang keluarga yang hanya dilihat berdasarkan pendidikan saja. Masih banyak indiator lainnya dari latar belakang keluarga, misalnya perceraian orang tua dan lain sebagainya. Selain itu, masih banyak juga faktor dan indikator lain yang bisa membuat para orang tua melakukan pola pengasuhan helicopter pada anaknya.

Untuk peneliti selanjutnya diharapkan agar dapat menyempurnakan hasil 
penelitian ini dari sisi penyempurnaan item. Selain itu, diharapkan agar peneliti selanjutnya dapat menemukan variabel lain selain latar belakang keluarga, karena hasil penelitian yang dilakukan peneliti menunjukan bahwa terdapat variabel lain yang berhubungan dengan variabel helicopter parenting.

\section{DAFTAR PUSTAKA}

Björklund, A., \& Salvanes, K. G. (2011).

Education and family background:

Mechanisms and policies.

Handbook of the Economics of

Education, 3(11), 201-247.

https://doi.org/10.1016/B978-0-

444-53429-3.00003-X

Camelia, R. N., Devi, G., \& Doriza, S. (2016). Perbedaan tingkat partisipasi sebagai akseptor keluarga berencana berdasarkan status sosial ekonomi keluarga.

JKKP (Jurnal Kesejahteraan

Keluarga dan Pendidikan), 2(1),

68.

https://doi.org/10.21009/JKKP.021 .10

Doriza, S. (2015). Ekonomi keluarga

(Pertama). Bandung: PT Remaja

Rosdakarya.

Doriza, S., Jannah, W., Yulastri, L.,

Maulida, E., \& Patrisia, D. (2018).
The relationship between parents'

educational background and

student attitude on

entrepreneurship. JKKP (Jurnal

Kesejahteraan Keluarga Dan

Pendidikan), 5(2), 147-153.

https://doi.org/10.21009/JKKP.052

.06

Galobardes, B., Shaw, M., Lawlor, D.

A., Lynch, J. W., \& Smith, G. D. (2006, January 1). Indicators of socioeconomic position (part 1).

Journal of Epidemiology and Community Health. BMJ

Publishing Group Ltd. https://doi.org/10.1136/jech.2004.0 23531

Grätz, M., Barclay, K., Wiborg, Ø. N., Lyngstad, T. H., Karhula, A., Erola, J., Conley, D. (2019).

Universal family background effects on education across and within societies. MPIDR Working Paper, 49(007), 1-82. https://doi.org/10.17045/sthlmuni. 7999148.v1

Hill, N. E., \& Taylor, L. C. (2004).

Parental school involvement and children's academic achievement pragmatics and issues. Curr. Dir. Psychol. Sci, 13, 161-164. https://doi.org/http://dx. 
doi.org/10.1111/j.0963-

7214.2004.00298.x.

Hyde, J. S., Else-Quest, N. M., Alibali, M. W., Knuth, E., \& Romberg, T. (2006). Mathematics in the home: Homework practices and motherchild interactions doing mathematics. J. Math. Behav, 25, 136-152.

https://doi.org/http://dx.doi.org/10. 1016/j.jmathb.2006.02.003. Impicciatore, R., \& Tosi, F. (2019). Student mobility in Italy: The increasing role of family background during the expansion of higher education supply. Research in Social Stratification and Mobility, 62(May), 100409. https://doi.org/10.1016/j.rssm.2019 .100409

Jang, J., Lee, S., Sung, M., \& Lee, J. (2016). Chapter 8 Family rela_tionships and communication in South Korea. In G. Jian \& G. Ray (Eds.), Relationships \& communication in East Asian cul_tures: China, Japan, and South Korea. Dubuque: IA: K.

Jeong, S. H., \& Eamon, M. K. (2009). A model of family background, Family process, Youth selfcontrol, and delinquent behavior in two-parent families. Journal of Family Social Work, 12(4), 323339. https://doi.org/10.1080/105221509 03261924

Kantrowitz, B., \& Peg, T. (2006). The fine art of letting go. Newsweek., 147(21), 1-6.

Khairunnisa, R., \& Trihandayani, D. (2018). Hubungan antara helicopter parenting dengan kesepian pada generasi milenial di masa emerging adulthood. Jurnal Ilmiah Penelitian Psikologi: Kajian Empiris \& Non-Empiris , 4(1), 32.

Klieme, E., Artelt, C., Hartig, J., Jude, N., Köller, O., Prenzel, M., Schneider, W., \& Stanat, P. (2010). Bilanz nach einem JahrzehntPISA 2009. Drawing a conclusion after a decade.

Münster: Waxmann.

Kwon, K.-A., Yoo, G., \& Bingham, G. E. (2016). Helicopter parenting in emerging adulthood: Support or barrier for Korean college students' psychological adjustment? Journal of Child and Family Studies, 25, 136-145. https://doi.org/https://doi.org/10.10 07/s10826-015-0195- 6. 
Lee, J., \& Kang, S. (2018). Perceived helicopter parenting and korean emerging adults' psychological adjustment: The mediational role of parent-child affection and pressure from parental career expectations. Journal of Child and Family Studies, 27(11), 36723686.

https://doi.org/10.1007/s10826018-1193-2

Lemoyne, T., \& Buchanan, T. (2011). Does "hovering" matter? Helicopter parenting and its effect on well-being. Sociological Spectrum, 31(4), 399-418. https://doi.org/10.1080/02732173. 2011.574038

Maccoby, E. E. (2007). Historical overview of socialization research and theory. New York: NY: Guilford Press.

Maccoby, Eleanor E. (1992). The role of parents in the socialization of children: an historical overview. Developmental Psychology, 28(6), 1006-1017. https://doi.org/10.1037/00121649.28.6.1006

Marano, H. E. (2004). A nation of wimps. Psychology Today.

Odenweller, K. G., Booth-Butterfield,
M., \& Weber, K. (2014).

Investigating helicopter parenting, family environments, and relational outcomes for millennials. Communication Studies, 65(4), 407-425. https://doi.org/10.1080/10510974. 2013.811434

Okray, Z. (2016). Helicopter parenting and related issues: Psychological well being, basic psychological needs and depression on university students. Current Research in Education, 2(3), 165-173.

Padilla-Walker, L. M., \& Nelson, L. J. (2012). Black hawk down?: Establishing helicopter parenting as a distinct construct from other forms of parental control during emerging adulthood. Journal of Adolescence, 35(5), 1177-1190. https://doi.org/10.1016/j.adolescen ce.2012.03.007

Patterson \& Garwick. (1994). Special Section Chronic Illness and the Family, 1-13.

Ream, R. K., \& Palardy, G. J. (2008). Reexamining social class differences in the availability and the educational utility of parental social capital. Am. Educ. Res. J, 45, 238-273. 
https://doi.org/http://dx.doi.org/10. 3102/0002831207308643.

Segrin, C., Woszidlo, A., Givertz, M., Bauer, A., \& Taylor Murphy, M. (2012). The association between overparenting, parent-child communication, and entitlement and adaptive traits in adult children. Family Relations, 61(2), 237-252.

https://doi.org/10.1111/j.17413729.2011.00689.x

Sewell, William H., and R. M. H. (1975). Education, occupation and earnings: Achievement in the early career. New York: Academic Press.

Van Ingen, D. J., Freiheit, S. R., Steinfeldt, J. A., Moore, L. L., Wimer, D. J., Knutt, A. D., ... Roberts, A. (2015). Helicopter parenting: The effect of an overbearing caregiving style on peer attachment and self-efficacy. Journal of College Counseling, 18(1), 7-20. https://doi.org/10.1002/j.21611882.2015.00065.x

Vinson, K. E. (2012). Hovering too close: The ramifications of helicopter parenting in higher education. SSRN Electronic Journal. https://doi.org/10.2139/ssrn.19827 63

Wang, D. B. (2004). Family background factors and mathematics success: A comparison of Chinese and US students. International Journal of Educational Research, 41(1 SPEC. ISS.), 40-54. https://doi.org/10.1016/j.ijer.2005. 04.013 